\title{
Exploration and Practice of New HSS Construction in the Public Affairs Administration Major of Medical Colleges: An example of Southwest Medical University
}

\author{
Xue Sun ${ }^{1}$, Weili Hu${ }^{1,2 *}$ \\ ${ }^{1}$ School of Humanities and Management, Southwest Medical University, Luzhou, Sichuan, China \\ ${ }^{2}$ Institute of education, Xiamen University, Xiamen, Fujian, China \\ *Corresponding Author.
}

\begin{abstract}
:
The new humanities and social sciences construction is an important part of the current higher education reform in China. It is an exploratory reform in the field of humanities and social sciences in the sense of adapting to the national strategic development and responding to the scientific and technological revolution. Taking the opportunity of the new humanities and social sciences construction, the major of public affairs administration in Southwest Medical University upgraded the concept, mode, content and means of personnel training, gave full play to the platform advantages of medical colleges, realized the deep integration of medicine and management, explored and constructed a new HSS construction program that integrates the three systems of "talent training, teacher workforce and quality culture", which is expected to provide reference for the advancement of higher education reform.
\end{abstract}

Keywords: Medical college, Public affairs administration, New HSS construction.

\section{CURRENT ISSUES}

The New Humanities and Social Sciences (HSS) Construction emphasizes on quality improvement of talent training, meeting the needs of economic and social development, the all-round development of people, and requires interdisciplinary integration. As a result, it raises new requirements for professional training in public affairs administration. Currently, in medical college-based training of public affairs administration professionals, we can't see 
sufficient cross-discipline integration between medicine, management and humanities and social sciences, good cross-field integration, highly effective means for developing students' comprehensive quality and practical ability, in particular: the lack of sufficient cross-discipline integration prevents medical colleges from giving full play to their own advantages, as a result they can't meet the needs for new HSS construction and healthy China construction, and lag behind in the great efforts of China in the reform and opening up, the modernization of the country, as well as in the anti-epidemic efforts by the Chinese people; also, the heavy reliance on monotonous traditional preaching-style teaching has resulted in students being under-developed in practical and application abilities, sentiment towards local development and global vision [1].

\section{BASIC CONDITIONS FOR NEW HSS CONSTRUCTION IN THE PUBLIC AFFAIRS ADMINISTRATION MAJOR OF SOUTHWEST MEDICAL UNIVERSITY}

Southwest Medical University was approved to grant bachelor's degrees in 1982, and master's degrees in 1993. In 2001, it began to jointly train doctoral students. In 2010, it was approved to establish a post-doctoral research station. In 2016, it was approved as a new doctoral degree-granting college and project construction unit in Sichuan Province. It vigorously promotes interdisciplinary and cross-field integration, attaches importance to education and teaching reform, and strives to cultivate a quality culture. The public affairs administration major of Southwest Medical University was approved to be established in 2003 and began to recruit undergraduates in 2004. It was approved in 2014 to grant MPA degrees, and began to recruit graduate students in 2015. After nearly 20 years of develop, the public affairs administration major has developed into a relatively mature non-medical major that has a strong connection with the medical field and covers four levels of higher education (master's degree, undergraduate, double degree, and undergraduate promotion).

2.1 Disciplinary Construction Focusing on Cross-disciplinary and Interdisciplinary Integration

Relying on the medical education resources of the college, this major has achieved cross-integration with four disciplines (management, basic medicine, clinical medicine, public health and preventive medicine), with teaching content involving multiple courses including humanities and social sciences, basic medicine, clinical medicine, preventive medicine, and management science. Compared with students of non-medical colleges, those received training in this major have a solid medical background, which is an obvious advantage in the management of health undertakings. Our courses are highly targeted because they highlight the application of the basic theories and skills of modern management science in health 
undertaking management. By emphasizing on practical ability and comprehensive quality training, making full use of the practical and teaching resources covering all levels of health institutions in Sichuan Province, strengthening practical exercise in the form of clinical internship, professional internship and graduation internship, we can comprehensively enhance students' comprehensive competence and problem-solving ability.

2.2 An Innovative Talent Training Model that Emphasizes on "Good Foundation, Strong Practice and Application Value"

In terms of talent training philosophy, the public affairs administration major emphasizes "good foundation, strong practice and application value". It asopts a $3+1$ mode, in which the first three years are used to consolidate the foundation for professional development through theoretical teaching, case study, and role-based practice, and the last year is used to strengthen practical exercise in the form of clinical internship, professional internship and graduation internship by making full use of the practical and teaching resources covering all levels of health institutions in Sichuan Province, so that students can quickly adapt to social demand and job requirements. In recent years, the innovation, communication and writing abilities of students of the public affairs administration major have been greatly improved, as proven by achievements including 3 national-level projects, 10 provincial-level projects, and being awarded 13 times in various innovation and entrepreneurship competitions.

\subsection{Cultivation of High-Quality Talents with Broad Employment Prospects}

Graduates of the major have maintained a more than $95 \%$ employment rate, and many of them choose to study for master's degree at domestic famous universities including Shanghai Jiaotong University, Nanjing University, Sichuan University, Lanzhou University, Southwestern University of Finance and Economics, etc. From the perspective of employment direction, most graduates take up positions in the HR departments, hospital offices and other administrative positions at institutions such as hospitals, health committees, health law enforcement and supervision organs. These graduates are dedicated to their jobs and have strong learning skills, communication, coordination and writing abilities, winning praises from most of their employers. In recent years, in order to further promote international development, the public affairs administration major has developed cooperative education programs jointly with foreign universities, including a $3+2$ training program with the University of Texas in the United States and a $4+1$ training program with Swansea University in the United Kingdom, all of which have further enhanced the social influence of the major.

\section{NEW HSS CONSTRUCTION IN THE PUBLIC AFFAIRS ADMINISTRATION}




\section{MAJOR OF SOUTHWEST MEDICAL UNIVERSITY: OBJECTIVES AND STRATEGY}

\subsection{Objectives}

\subsubsection{Realizing innovations in talent training concept}

We should establish a student-centered and practical ability-oriented talent training system, and adhere to the philosophy of people-oriented education by virtue, and comprehensive development of people. In professional talent training in the public affairs administration major of medical colleges, we need to take the initiative to innovate, to seek change and pursue excellence from the perspective of making achievements and solving problems in a way that reflects Chinese characteristics, global vision, technical and humanistic concepts [2].

3.1.2 Constructing a new model of new HSS construction in the public affairs administration major of medical colleges

We should optimize the training model of liberal arts talents, explore talent training conditions, approaches, methods, curriculum systems, and quality standards that are suitable for the construction of a modern public affairs administration major [3]. We need to provide students with diversified profession choices and cross-disciplinary learning opportunities, to build a diversified talent training platform that highlights practical abilities, and adapt to the demand for management talents in the health sector.

3.1.3 Improving the quality of the liberal art teacher workforce of public affairs administration major

We should continuously improve the quality and competitiveness of the existing teacher workforce, and make plans and arrangements for the professional development of young and middle-aged teachers according to the characteristics of new HSS construction, strengthen the construction of academic community, encourage interdisciplinary cooperation, and stimulate the innovative potential and vitality of the teachers. Also, we need to bring in fresh blood by introducing professional talents from other disciplines, and improve the new liberal arts vision and literacy of existing teachers, so as to ensure the sustainable development of the teacher workforce [4].

3.1.4 Improving the guarantee system for professional development in the field of public affairs administration 
We should actively adapt to the demand of modern development of national governance system and capabilities. [5] Taking the opportunity of new HSS construction, we need to accurately understand the rules of discipline construction and talent training in the public affairs administration major of medical colleges, optimize the major's construction management system, promote the establishment of a flexible new HSS construction management system, do a good job in localized management and governance practices that reflect China's position, wisdom and domestically developed theories.

3.2 New HSS Construction in the Public Affairs Administration Major of Southwest Medical University: Strategy

Taking the opportunity of the new HSS construction and healthy China construction, we should adhere to the value philosophy of virtue and people-oriented education, and actively adapt to the demand of economic and social development and changes in production and lifestyles brought about by the new technological revolution, upgrade and transform the concept, model, content and means of professional training in public affairs administration major of medical colleges by making reasonable use of modern information technology, so as to give full play to the platform advantages of medical colleges, realize the deep integration of medicine and management, construct a new HSS construction program that integrates the three systems of "talent training, teacher workforce and quality culture", and cultivate a large number of high-quality health management personnel. Fig 1 shows the schematic framework of new HSS construction in the public affairs administration major of Southwest Medical University.

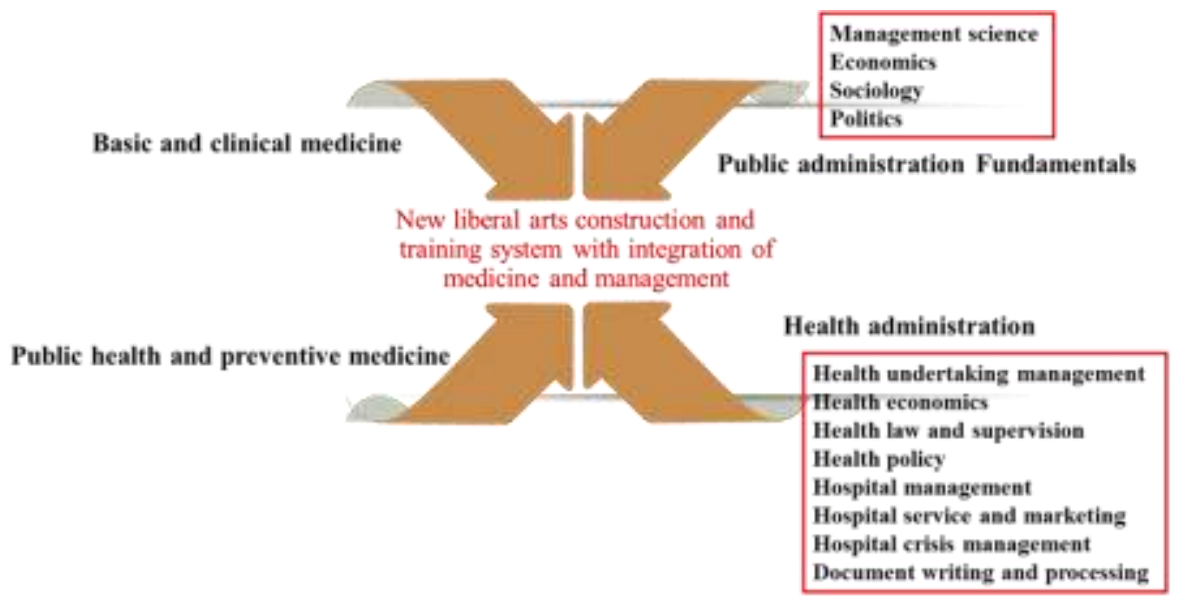

Fig 1: The schematic framework of new HSS construction in the public affairs administration major of Southwest Medical University

IV. NEW HSS CONSTRUCTION IN THE PUBLIC AFFAIRS ADMINISTRATION 


\section{MAJOR OF SOUTHWEST MEDICAL UNIVERSITY: PRACTICAL MEASURES}

\subsection{Talent Training Reform}

\subsubsection{Improve the curriculum system and optimize the talent training model}

We should adjust our talent training programs according to the needs of new HSS construction and the requirements of the "Six Excellence and One Top" plan 2.0, and formulate talent training programs and curriculum syllabus based on the result-oriented education philosophy and the actual situation of our college, including clearly defining the school system, credit system, and curriculum system.

\subsubsection{Create high-quality courses and improve teaching quality}

We should create high standard quality courses one by one, examples of which include "Health Undertaking Management", "Health Economics", and "Hospital Management", and establish high-level teaching teams for each of these courses.

\subsubsection{Build a high-level teaching platform to improve students' practical ability}

Starting from the integration of production and education, including college-hospital and college-enterprise cooperation, we aim to accelerate teaching platform construction and promote collaborative education.

4.1.4 Strengthen scientific research ability and promote education and teaching reform

Relying on the college-based platform for scientific research, we should build academic teams composed of young teachers, professors, and doctors, make clear the direction of disciplinary study and strive to produce distinctive and high-quality research results.

4.1.5 Strengthen exchanges and cooperation, and further develop comprehensive ability of students in the major

We should use National Organizational Management Competition and other activities to enhance students' mastery and application of professional knowledge, and their abilities in innovation, communication and writing. Fig 2 shows the new HSS construction talent training system for public affairs administration major in medical college. 


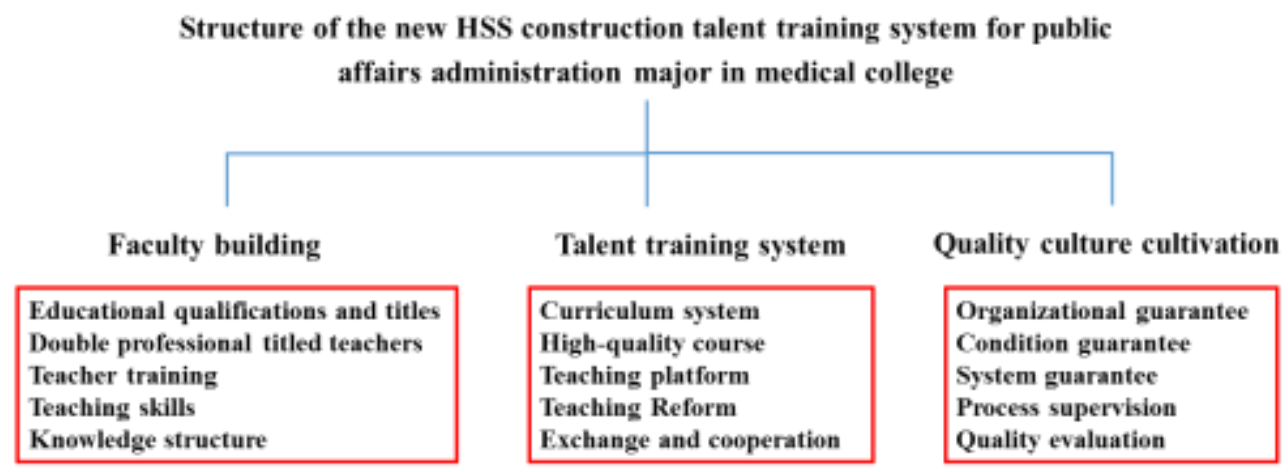

Fig 2: New HSS construction talent training system for public affairs administration major in medical college

\subsection{Faculty Team Building}

4.2.1 Take two measures simultaneously to optimize the position structure of teacher workforce

We should take the "internal and external" approach to strengthen the introduction and training of young and middle-aged teachers, continuously strengthen the teacher work force and improve its position and education structures.

\subsubsection{Strengthen the construction of teaching team with "double-position" teacher force}

Strengthen the construction of "double-position" teacher force, including organizing teachers to participate in vocational qualification trainings and examinations, arranging for young and middle-aged teachers to take off-the-job trainings and on-the-job practices, hiring health management experts to act as part-time teachers in our college, inviting teachers from other disciplines and majors to teach for the students of this major.

\subsubsection{Enhance teacher training and related exchanges and cooperation}

We should broaden teachers' visions and improve their professional abilities by regularly sending selected young teachers to participate in domestic and foreign trainings, academic conferences, and conduct related reporting and exchange activities.

\subsubsection{Improve teaching skills through multiple channels}

We should continuously improve the systems for collective lesson preparation and learning 
from class visits, as well as archiving of teacher training records, and actively organize teachers to participate in municipal, provincial, and national teaching competitions.

\subsubsection{Improve the knowledge structure of teachers}

We should strengthen interdisciplinary integration by improving the new faculty vision on liberal arts, and encourage teachers of the major to make self-improvements by improving their cultural attainment and knowledge structure, as well as actively carry out cross-disciplinary and cross-subject studies to promote the discipline-subject integration and development.

\subsection{Quality Assurance System}

\subsubsection{Improve organizational guarantee}

Enhance organizational guarantee by setting up a leading group for the reform of teaching quality assurance system, a teaching supervision group, a teaching quality consulting group, a major-specific quality improvement working group and a curriculum group, all with clearly defined responsibilities and authorities.

\subsubsection{Improve conditions guarantee}

We should strengthen the construction of the teacher work force, teaching facilities and platforms in reference to the requirements of major-related national standards, general certification standards and supplementary standards.

\subsubsection{Enhance system guarantee}

We should develop and improve the teaching supervision work system for new HSS construction, which includes a major-specific teaching quality evaluation system, the system of beginning, mid-term, and final inspections, the internship management system, the graduation design (thesis) management system.

\subsubsection{Whole process supervision of course teaching}

We should use measures such as teaching inspection, class visits by leadership, supervisors and peers to supervise and monitor the teaching of teachers and the learning of students in three stages: pre-class preparation, in-class teaching and after-class feedback. 
4.3.5 Evaluation and continuous improvement of teaching quality

We should continuously monitor and improve teaching quality through evaluation of course teaching output, students' learning output, professional education output and teachers' teaching quality.

\section{NEW HSS CONSTRUCTION IN THE PUBLIC AFFAIRS ADMINISTRATION MAJOR OF SOUTHWEST MEDICAL UNIVERSITY: RESULTS}

\subsection{Significant Improvement in the Quality of Talent Training}

With the optimization of the curriculum system and the improvement of the talent training model, our training quality has been significantly improved. In the past three years, the employment rate of students in this major has exceeded $94 \%$, with m0st of those still unemployed preparing to continue their studies. The graduates are well received by employers at the public and private sectors, with employers being satisfied with their work performance, professional competence and quality of these graduates and believing that they are competent for medical and health-related management and service works. The academic achievements made by the students of this major include 3 national-level projects, 10 provincial-level projects, 25 school-level projects, and being awarded 13 times in various innovation and entrepreneurship competitions. By having "Health Undertaking Management" rated as a school-level excellent course, and "Health Economics" and "Social Security Studies" rated as school-level gold courses with published high-quality professional textbooks, our teaching level has also been significantly improved. In addition, we have established 1 new internship base and 2 new practice bases, and a laboratory for public administration/public policy case study; and actively participated in professional teacher training and academic exchanges to expand our professional influence.

\subsection{Rapid Development of Teacher Workforce}

Among the 15 teachers in this major, 60\% have senior titles (9) and $60 \%$ have obtained a doctorate degree or are currently studying for a Ph.D. (9), 12 have obtained vocational qualification certificates in related industries; we have also hired more than 10 health management experts as part-time teachers of this major to effectively improve students' practical abilities. In recent years, the teachers of this major have presided over 3 projects at the provincial and ministerial level and above, and more than 10 projects at the department and bureau level; published nearly 100 high-level research papers, more than 10 CSSCI papers, and more than 30 articles in Chinese core journals. 


\subsection{Continuous Improvement of the Quality Assurance System}

Our quality assurance system has been further improved, with the whole faculty having a more comprehensive recognition of the quality culture centered on personnel training. Over the past three years, we have had more than 300 teaching evaluations and no teaching accidents. By further standardization of the teaching process and making orderly progress in various teaching links, our teaching quality and student satisfaction have been greatly improved.

\section{NEW HSS CONSTRUCTION IN THE PUBLIC AFFAIRS ADMINISTRATION MAJOR OF SOUTHWEST MEDICAL UNIVERSITY: FEATURES AND EXPERIENCE}

\subsection{Main Features}

\subsubsection{A discipline construction model that is in line with China's development trend}

China has entered a new era of socialist construction, which must be clearly reflected in the new HSS construction [6]. By inheriting and developing traditional advantages, absorbing the essence of advanced knowledge in humanities and social science, and giving full play to the unique advantages a medical college has in the construction of the public affairs administration major, this project aims to cultivate high-level management talents in the field of health and medicine in a way that fits China's current development trend in terms of guiding ideology, discipline system, academic discourse, etc., and fully reflects the profound culture background and style of China [7].

\subsubsection{A discipline system that emphasizes integration}

New HSS construction emphasizes the integration of multiple disciplines. Responding to the needs for new HSS construction and healthy China construction, other than integration with disciplines such as literature, management science, medicine, which is in line with the trend of cross-integration between natural science and social science disciplines, this project puts more emphasis on cross-field integration in the process of talent training, improving the overall quality and ability of public affairs administration students, in particular their practical ability and problem-solving ability in the field of hygiene and health, and developing a strong sentiment towards local development and global vision [8].

6.1.3 Practice-oriented training of public administration talents in medical college 
In response to the realistic needs of the country and society, this project is geared towards cultivating compound management talents that are urgently needed in the field of health care, so as to solve the most concerned issues of the people and contribute to the construction of a "healthy China". [9] In order to improve students' practical and application abilities in solving practical problems, it is required to emphasize practicability in aspects such as talent training concept/plan, curriculum system, textbook development, practice platform and teaching methods.

\subsection{Experience}

\subsubsection{Build a quality brand for talent cultivation through the sublimation of ideas}

New HSS construction in the public affairs administration of medical colleges should focus on the core concept of "improving quality and meeting demand", be aimed at enhancing students' ability to solve practical problems, and strengthen their sentiment towards local development and global vision. Putting "people" as the center, we must continue to pay attention to the value and significance of students, and to build a quality-focused education brand and culture.

6.2.2 Optimize education and teaching contents and establish a "three in one" practical education system

We should explore the implementation of a "full process" tutoring model and form a comprehensive talent training system backed by resource support, curriculum system, management services, and quality assurance. At the same time, we need to raise funds for practical education from multiple sources, so as to guarantee its sustainable development and offer effective incentives. [10] Furthermore, we should strengthen the cooperation between all teachers, class guides, counselors, and academic staff to form a joint force for practical education.

\subsubsection{Add variety to talent training methods and ways of education}

We should make innovations in ways of classroom teaching of the major. [10] In terms of new HSS construction related theoretical classroom teaching in the public affairs administration major of medical colleges, it is required to actively integrate practical contents, promote case teaching, enrich teaching methods, create practice bases with distinctive features, strengthen the construction of the second classroom education system, actively explore new forms and ways of new HSS construction, make flexible use of scientific and technological 
means to promote the refinement and scientific rationalization of education models, and comprehensively improve the practical and application abilities of students of this major.

\section{ACKNOWLEDGEMENTS}

This research was supported by Postdoctoral Science Foundation of China (NO. 2021M691881) and 2021 Project of the 14th Five Year Plan for Social Science Research in Sichuan Province (NO. SC21JD016).

\section{REFERENCES}

[1] Huang QB, Tian XM (2020) The Source, Characteristics and Path of "New Liberal Arts" Construction. Journal of Suzhou University: Educational Science Edition 8(2):75-83.

[2] Chen ZM (2019) Practice Changes and Discipline Transformation of Public Affairs Administration. Journal of China Public Administration Review 1(3):41-48.

[3] Lv WX, Ni JR (2021) The Construction of Postgraduate Curriculum System of Public Administration in Universities under the Background of "New Liberal Arts" Construction. Journal of Public Relations World 8(15):26-29.

[4] Yan B, Zheng KL, Shi CY (2019) Optimization of talent training mode of public administration subject under the background of new liberal arts. Journal of Economic Research Guide 36(17):92-94.

[5] Du H (2020) Optimization of administrative Management professional Talent Cultivation mode under the Background of new liberal arts. Journal of Education observation 9(29):28-29.

[6] Ning Q (2020) Social Needs and Core Tasks of New HSS Construction. Journal of Shanghai Jiaotong University: Philosophy and Social Sciences Edition 28(2):13-17.

[7] Cao TS (2020) The Utility of New HSS Construction: Knowledge Production and Education. Journal of Shanghai Jiaotong University: Philosophy and Social Sciences Edition 28(1):15-18.

[8] Su H, Liu Q (2020) Discussion on laboratory construction of public Administration specialty in colleges and universities under the background of new liberal arts. Journal of Experimental technology and management 37(7):246-249.

[9] Qi BH (2020) New liberal arts construction and public Service management professional talent training. Journal of Cultural and Educational Materials 36(18):148-149.

[10] Zhang P, Su M. Direction of Practice Education Optimization in Public Administration Major under the Background of "New Liberal Arts" Construction. Journal of China Metallurgical Education 202(1):110-114. 